\section{Análise do Modelo Brasileiro}

Por Celso Furtado. Rio de Janei. ro, Editora Civilização Brasileira, 1972, 122 p.

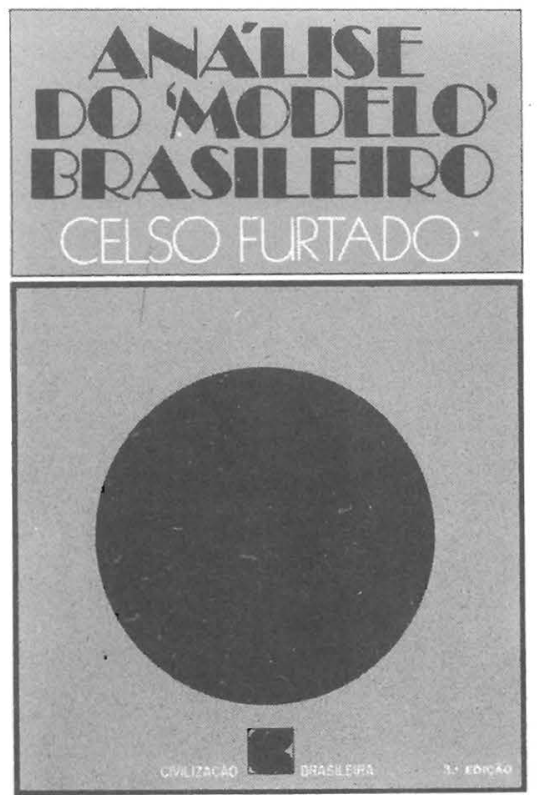

A bibliografia especializada fornece-nos, infelizmente, poucos estudos sérios a respeito das transformações ocorridas no Brasil a partir da década de 60. Por outro lado, análise superficiais, panfletárias até, abundam, dificultando ao estudioso, ou ao mero interessado, um entendimento maior da situação histórico-estrutural pela qual passa este país em desenvolvimento, segundo uns, e em direção à mera modernização, segundo outros. Os sociólogos e economistas preocupam-se, atualmente, em avaliar aspectos marginais da realidade brasileira, procurando afastar-se de afirmativas mais comprometedoras; torna-se, assim, patente a falta de análises profundas e objetivas quanto ao real significado do Movimento de Março, e das suas conseqüências nos diversos subsistemas do macrossistema social.

Foi natural, portanto, que se aguardasse com certa ansiedade, uma análise do "modelo" brasileiro de desenvolvimento, elaborado por um economista e pensador renomado, Celso Furtado. Criador da Sudene, artífice do Plano Trienal de Desenvolvi- mento, ex-Ministro-sem-pasta, e atualmente professor nas universidades de Harvard e Sorbonne, poder-se-ia esperar do Professor Furtado uma avaliação clara e objetiva das tendências que orientaram e orientam o Brasil durante os nossos dias. No entanto, após uma leitura cuidadosa do pequeno volume intitulado Análise do "modelo" brasileiro, chega-se à conclusão de que ainda assim falta um estudo mais profundo da realidade brasileira, pois questões básicas continuam a pedir respostas e explicações. O Professor Fur. tado reúne e sintetiza as muitas e conhecidas críticas dirigidas à orientação socioeconômica do atual Governo, mas, raramente consegue fazer o que se denomi. na uma "síntese criadora". Muitas de suas idéias e temas remontam às suas primeiras obras, como também às tradicionais teses da Cepal; é interessante, por outro lado, notar como, em determinados momentos, estas mesmas teses mudam de conteúdo para se adaptarem às situações radicalmeite novas.

O volume reúne dois ensaios distintos, sendo o primeiro aquele que dá nome à obra, e o segundo uma breve análise do sistema agrário, intitulado $A$ estrutura agrária no subdesenvolvimento. brasileiro. É ao primeiro destes ensaios que dirigimos a nossa atenção.

O Professor Furtado esquiva-se da análise da "dependência" ao conceituar o subdesenvolvimento brasileiro; opta, isto sim, pela utilização da variável "tecnologia" como fator determinante da situação histórico-estrutural na qual está inserido o Brasil. A Revolução Industrial é definida dicotomicamente, pois significa modificações profundas tanto nos padrões de consumo como também nos processos tecnológicos de produção. O subdesenvolvimento seria caracterizado, assim, pela modificação nos padrões de consumo, sem uma transformação concomitante do nível dos processos produtivos. A problemática do subdesenvolvimento seria "resolvida" através da incorporação de uma tecnologia "autenticamente nacional"; no entanto, Furtado não fornece quaisquer indícios sobre a forma pela qual poderia realizar-se este fenômeno.
A discussão, que pensávamos fosse algo estéril, sobre a existência ou não de uma burguesia nacional, aparentemente fascina 0 Professor Furtado, pois se dedica a negar a presença desse grupo substituindo-o no entanto, por um setor industrial, "elemento hegemônico do sistema nacional de poder". Infelizmente, não conseguimos discernir a presença desse grupo, a menos que o Professor Furtado tenha confundido, imperdoavelmente, este setor industrial com a chamada "tecnocracia".

O papel das Forças Armadas nas transformações havidas nos anos passados é praticamente esquecido, sendo-lhes dedicado apenas a afirmativa de que constituem um "partido político sui generis". O leitor que vive o diaa-dia no Brasil, dificilmente consegue conceber uma análise do modelo de desenvolvimento brasileiro sem um estudo profundo da posição e da função das Forças Armadas nos países em desenvolvimento, e, em especial, no Brasil. Resta-nos o consolo de que que $\circ$ Professor Furtado entra em maiores detalhes ao explicitar o "tripé" sobre o qual se assenta a orientação econômica do atual Governo.

A nova estratégia, que veio atender ao problema fundamental do desenvolvimento nos meados da década de 60, isto é, a criação de condições para a retomada do processo de industrialização, gira em torno de três pontos fundamentais:

a) em primeiro lugar, a reorientação do processo de concentração de renda, a fim de adequar o perfil da demanda às condições estruturais do setor secundário;

b) a redução do salário real básico de forma a reduzir a diferença entre esta taxa de salário e o "custo de oportunidade" do trabalho; e,

c) o fomento à exportação de produtos industriais visando a absorver a capacidade ociosa, e compensar a queda na demanda, devido às modificações havidas no perfil de consumo.

Cabe ressaltar, aqui, a discussão sobre o papel desempenhado pela inflação no processo de desenvolvimento brasileiro. Tradicionalmente, os estruturalistas concebiam a inflação como elemento estrutural do subdesenvolvimento, refletindo a incapa- 
cidade do setor agrário para abastecer satisfatoriamente a crescente demanda dos aglomerados urbanos. $O$ Professor Furtado abandona esta tese, preferindo entender a inflação como "instrumento" da politica econômica governamental, pois, segundo suas próprias palavras, "graças a ela foi possivel aumentar o excedente que alimentou à expansão dos investimentos públicos". Assim, a inflação se colocaria ao lado das políticas cambial, fiscal, creditícia e salarial, podendo ser eliminada a um "toque de vara mágica"

Considęravel atenção é dedicada à problemática da política salarial ondése chega à conclusão, algo surpreendente, de "... que os salários hajam continuado a baixar, constitui simples aspecto da política social, sem qualquer vínculo com o mecanismo de expansão."

A parte final do Cnsaio é dedicada ao exame de três tópicos: os requisitos para que se mantenha a expansão, a determinaçãs da especificidade do sistema ca pitalista brasileiro, e finalmente, as possibilidades de generalizaçãó do modelo.

Qúanto às condições necessárias para um crescimento autosustentado, o Professor Furtado cita três requisitos indispensáveis, a saber:

a) que a capacidade de pagamento no exterior aumente o uma taxa superior ao PIB;

b) que o setor público se mantenha em expansão por depender deste a criação de empregos; e,

c) que o setor industrial se mantenha em crescimento.

O sistema capitalista brasileiro é entendido como sendo uma variante da economia capitalista "em que é a própria remuneração do capital ... que alimenta a demanda de bens finais originários das indústrias em que mais rápido é o progresso técnico". O Professor Furtado ressalta a insuficiência do "anel de feedback fundamental" responsável pela tendência à estagnação, à frenação do crescimento, etc.; este anel compreende a interação que existé entre o flúxxo de salários e o crescimento da produtividade do trabalho.

Quanto às possibilidades de generalização do modelo brasileiro de desenvolvimento, 0 Professor Furtado mantém uma atitude bastante cética já que falta aos demais países látino-americanos os requisitos básicos: uma relativa dimensão demográfica e uma baixa renda per capita. Segundo o autor, "a busca de caminhos distintos da parte de países como - Peru e o Chile é, menos do que se pensa, uma opção voluntária", ilustrando a falta dos requisitos supracitados.

A experiência mexicana de desenvolvimento distingue-se do atual surto de desenvolvimennto brasileiro: a evolução política mexicana, com a sua revolução que deslocou a velha aligarquia, e a incorporação de novos grupos políticos já comprometidos com o processo de industrialização forjou uma conjuntura diversa daquela que observamos no Brasil. A proximidade dos Estados Unidos, a escassez de terras aráveis e a modernização do setor agricola impedem uma repetição do modelo; México, assim, se caracterizaria por ser "um país de elite burocrática de elevados salários".

Argentina, segundo Celso Furtado, afasta-se tanto do modelo brasileiro como do modelo mexicano. A oferta inelástica de mãode-obra, uma experimentada e sólida organização sindical, e um setor industrial altamente controlado de fora levam à conclusão de que "o desenvolvimento é, na Argentina, muito mais um fenômeno de dependência externa que de dualismo estrutural".

O ensaio finda assinalando as mudanças havidas nas chamadas "tendências estruturais" dos últimos anos, com o questionamento do "sentido do desenvolvimento" e da "qualidade da vida" produzida pelo atual sistema industrial. Segundo Furtado, na medida em que os paises industrializados questionam seu próprio "modo de vida", os subdesenvolvidos perderão interesse no paradigma representado pelos desenvolvidos. Parece-nos que o autor abandona aqui suas teses mais nacionalistas, preferindo esperar por mudanças nos pólos hegemônicos, mudanças estas que certamente se farão sentir nos países periféricos.

Franklin Lee Feder
Social Origins of Dictatorship and Democracy: Lord and Peasant in the Making of the Modern World

Por Barrington Moore Junior. Boston, Beacon, 1967. 559 p.

Se a maioria dos estudos sobre a implantação do capitalismo focaliza essencialmente a atuação da burguesia nesse processo, Barrington Moore Jr. mostra a importância do papel desempenhado pelas classes agrárias (aristocracias fundiárias e camponeses) nesse mesmo processo.

A preocupação essencial do autor é demonstrar como a atitude dessas classes agrárias, em seu relacionamento mútuo e com as outras classes sociais, no processo que ele define em sintese como de "modernização", condicionou todo. o desenvolvimento político que resultou nos atuais regimes políticos das "sociedades industriais modernas". Considerar a dinâmica das relaçōes sociais no campo e suas transformações frente ao advento do capitalismo como determinante fundamental da evolução política contemporânea constitui a nossso ver uma metodólogia "incomum", pois foge aos padrōes usuais' de análise que buscam, em geral, explicação para os fenômenos políticos atuais na dinâmica das ' ré lações sociais-urbanas, ou "pelo menos dão peso moior a esse tipó 